Los discursos del proyecto

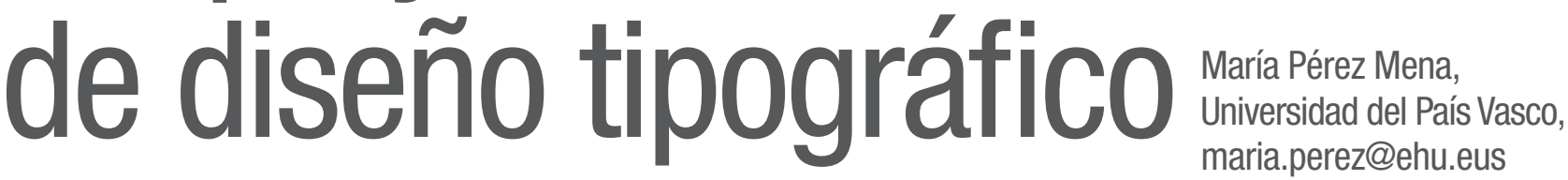

RESUMEN

El ser humano es creativo por naturaleza. Su capacidad para crear nuevas realidades a partir de otras existentes es una actividad intelectual y altamente compleja. Por este motivo, el diseñador/a requiere comprender los mecanismos mentales de creación así como la naturaleza de aquello que se pretende proyectar. Entendiendo la tipografía como sistema cultural, y en base a lo anterior, en este trabajo definimos la tipografía como una red interdisciplinar y analizamos el proceso creativo desde la mirada dirigida por el proyecto, con el objeto de identificar aquellos elementos esenciales que ayuden a potenciar decisiones controladas y no arbitrarias.

\title{
Palabra clave
}

metodología proyectual; proyecto de diseño; diseño tipográfico; creatividad

\section{The discourses of a typeface design project}

\section{ABSTRACT}

Human being is intrinsically creative. His/her capacity of creating new realities from other ones is an intellectual and highly complex activity. Because of that, designer needs to understand mental mechanisms of creation as well as the essence of what it is intended to design. Understanding typography as visual culture, and related to what that being said, this article aims to define typography as an interdisciplinary network. We also will analize creative process from the look directed by the project with the purpose of identify those basic elements that may help to strengthen not arbitrary but controlled decisions.

Keywords

design methodology; design; typeface design; creativity 


\section{Introducción}

El ser humano se distingue del resto de especies por su capacidad de reflexionar sobre su entorno y tener la voluntad y la destreza de actuar sobre él para mejorar su habitar en el mundo, mediante la creación de una naturaleza paralela o artificial. Esta capacidad inventiva llamada creatividad, es desarrollada a través de proyectos (Marina, 1993, p.35). Así, pues, entendemos el proyecto como la acción planificada de creación de un orden nuevo deseado que dirige nuestra mirada hacia el qué y el por qué a razón de nuestros objetivos, esto es, del para qué; dejando que el futuro anticipado nos guíe.

Partiendo de este principio, situamos el diseño en el cómo del proyecto, pues es la actividad que determina el orden de las cosas, estableciendo un sistema de relaciones constantes «entre nosotros y los ambientes que ocupamos, los objetos que utilizamos y los mensajes que integramos" (Costa, 2014, p.89).

En este sentido, desarrollar un proyecto de diseño conlleva la aplicación de una compleja red de conocimientos específicos y no específicos sobre aquello que deseamos proyectar. Entender cómo se conjugan estos conocimientos para agilizar el proceso y garantizar unos resultados efectivos ha sido, sobre todo desde mediados del siglo XX, del interés de diseñadores y académicos de diversas disciplinas.

Esta investigación tiene, así, por objeto, comprender la naturaleza de estos conocimientos y la pertinencia de su aplicación en un proyecto de diseño. Para ello, hemos acotado nuestra investigación al proyecto de diseño tipográfico, exponiendo como estudio de caso el proyecto de diseño de la tipografía corporativa EHU, realizada para la Universidad del País Vasco/Euskal Herriko Unibertistatea (UPV/EHU) como parte de su gestión de marca y llevada a cabo por el Grupo de Investigación en Diseño Gráfico y Tipografía «Letraz» a través de los proyectos de investigación financiados UPV/EHUPES 11/31 y EHU 13/45.

\section{Fundamentación teórica}

Cada proyecto de diseño transforma nuestra cultura material a través de una manera determinada entre muchas posibles. No obstante, todo proyecto de diseño comparte unos principios generales que nos facilitan su comprensión, lo que nos puede ayudar a mejorar su control general y concreto (Cross, 1999, p.46) y dejar un espacio más limitado al azar.

Este planteamiento permite entender el proceso proyectual no solamente como algo que puede ser producido, sino también como algo que puede ser reproducido (Martí, 1999, p.87), de modo que podemos entender cada una de las acciones realizadas en el proceso como conjuntos similares de acciones proyectuales y no como actos aislados. Esto facilita que, lejos de limitarnos a captar la experiencia inmediata del proceso relativo a cada proyecto, podamos alejarnos y observar en otros procesos rasgos comunes que pueden sernos útiles aplicados en éste.

En este punto, consideramos de interés mencionar la idea de método desde su origen etimológico derivado de los vocablos griegos 'meta' (a lo largo de o a través de) y 'ódós' (camino). Plantear, así, el método como el camino que nos lleva a un fin determinado propuesto de manera previa nos conduce a salir del estancamiento de su formulación como técnica mecánica que proporciona soluciones prefabricadas para comprenderlo como una ayuda estratégica dirigida a obtener una mayor comprensión -y por lo tanto, un mayor control- del proceso proyectual. Bonsiepe (1978) formula al respecto:

Dos realidades esperamos de la metodología: que nos ofrezca una serie de directrices y que nos aclare la estructura del proceso proyectual. Esto implica a su vez una proyección praxeológica y una componente hermenéutica. La metodología del proyectar se funda en la hipótesis de que en el proceso proyectual, incluso en la variedad de las situaciones problemáticas se halla enterrada una estructura común, es decir, hay todas unas constantes que vienen a configurar, por así decirlo, una armadura, haciendo abstracción del contenido particular de cada problema proyectual singular. (pp.146-147)

El caluroso debate en torno a los métodos que tuvo lugar durante el siglo $X X$-con especial intensidad, a partir de mediados de siglo-, estuvo fundamentalmente representado por los defensores de la aplicación de postulados científicos en la resolución de problemas —los llamados «metodólogos»- por un lado, y, por otro, por aquellos que prefieren recuperar la vigencia de la tipología adaptada a las necesidades de los nuevos tiempos.

El planteamiento de los primeros planteaba la determinación formal como resultado de un proceso lógico en el cual convergen las necesidades funcionales y las correspondientes correlaciones tecnológicas y formales.

Este planteamiento implicaba elaborar toda una serie de métodos objetivos —analíticos - que fueron más apreciados por los especialistas en métodos que por los propios diseñadores (Martí Font, 1999, p.224). Es en este punto donde la 
11

María Pérez Mena

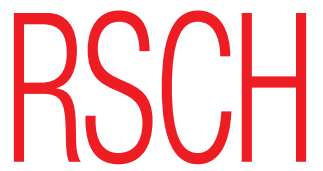

grafica: formulación de Alan Colquhoun toma un especial interés al aceptar la necesidad de aplicar ciertas leyes generales al proceso de diseño -como postulaban los «metodólogos»- pero en conjunción con una toma de decisiones inscritas en el ámbito de la libre elección que está condicionada, que no determinada, por la experiencia anterior; es decir, por el conjunto de técnicas, funciones utilitarias, influencias culturales... que como seres inteligentes somos capaces de identificar, almacenar y catalogar en la memoria a modo de ejemplos, modelos y tipos.

Para Charles S. Peirce (1987), estos modelos son comparados y crean una enorme red de conexiones significantes como respuesta al incansable sistema de preguntas que supone el proyecto, cuyo razonamiento lógico no seguiría ya, por lo tanto, unas pautas únicamente deductivas -analíticas- como proponen los defensores del «método", ni inductivas - sintéticas- como plantea el sistema tipológico, sino abductivas, es decir, mediante la capacidad del individuo para percibir estímulos de manera intuitiva y organizarlos de manera consciente en base a los objetivos propuestos, dirigiendo así su conducta en el hacer para llegar a dar siempre con una solución adecuada.

Peirce (Hoffmann, 1998) explica este proceso de la siguiente manera:

[...] no hay sino tres clases elementales de razonamiento. La primera, que yo llamo abducción [...] consiste en examinar una masa de hechos y en permitir que estos hechos sugieran una teoría. De este modo ganamos nuevas ideas; pero el razonamiento no tiene fuerza. La segunda clase de razonamiento es la deducción, o razonamiento necesario. Solo es aplicable a un estado ideal de cosas, o a un estado de cosas en tanto que puede conformarse con un ideal. Simplemente da un nuevo aspecto a las premisas [...] El tercer modo de razonamiento es la inducción o investigación experimental. Su procedimiento es este: cuando la abducción sugiere una teoría, empleamos la deducción para deducir a partir de esa teoría ideal una promiscua variedad de consecuencias a tal efecto que si realizamos ciertos actos, nos encontramos a nosotros mismos enfrentados con ciertas experiencias. Cuando procedemos a intentar esos experimentos, y si las predicciones de la teoría se verifican, tenemos una confianza proporcionada en que los experimentos que aún no se han intentado confirmarían la teoría. Yo afirmo que estor tres son los únicos modos elementales de razonamiento que hay. (p. 42) Figura 1.

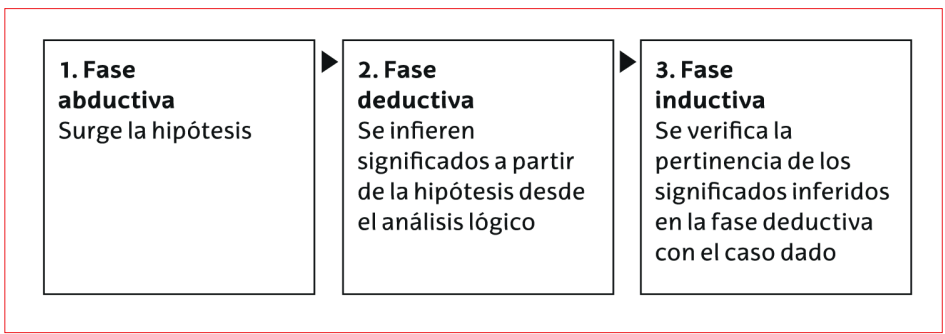

Figura 1. Proceso de razonamiento según Charles S. Peirce.

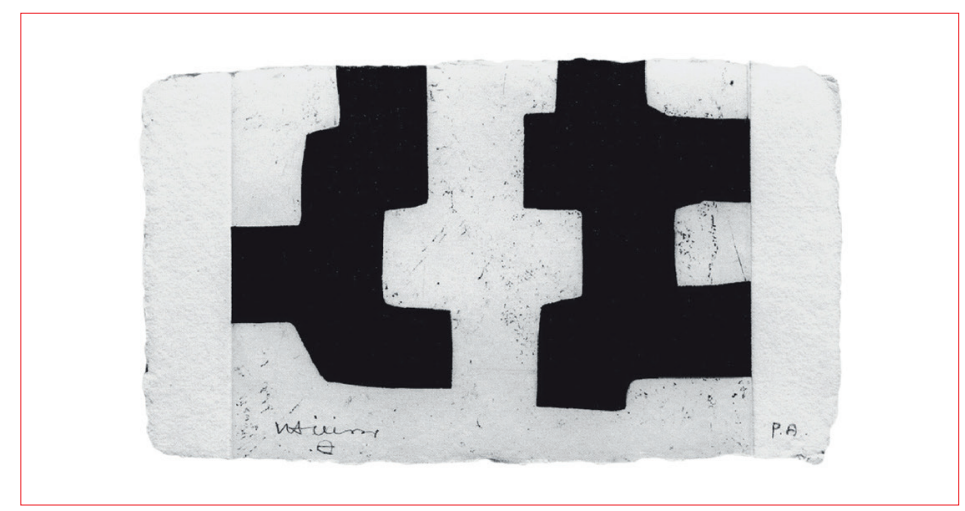

Figura 2. Idigi I. Eduardo Chillida, 1982.

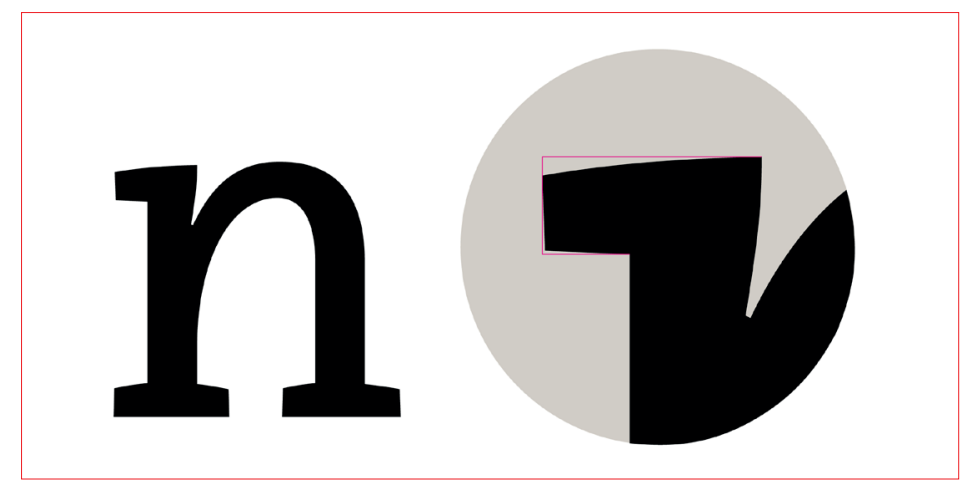

Figura 3. Interpretación de la obra de Chillida en términos tipográficos.

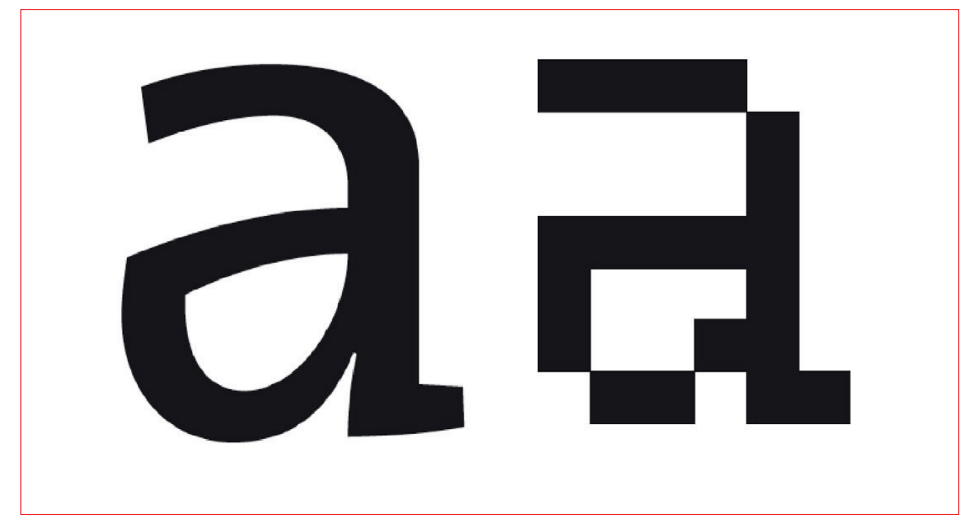

Figura 4. Traducción de la letra a mapa de bits (baja resolución en pantalla). 


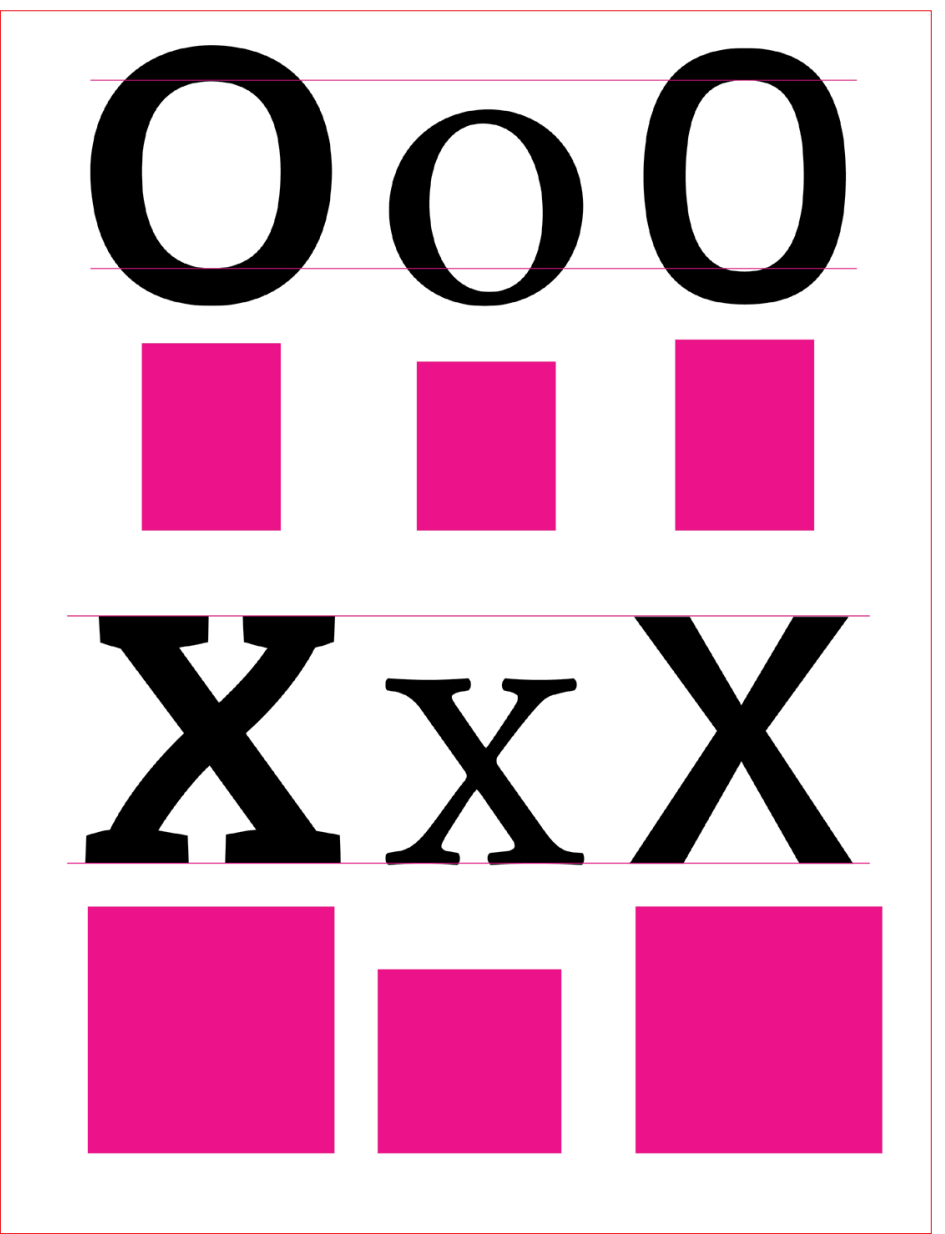

Figura 5. Comparación de amplitud de ojo medio (arriba) y de altura de equis (abajo) de la tipografía EHU (izquierda) con Garamond, tradicionalmente empleada para cuerpos de lectura en soporte impreso (centro), y con Fago, específicamente diseñada para su uso en pantalla (derecha).

Por lo tanto, para Peirce, la abducción consiste en estudiar los hechos e idear una teoría que los explique. En este sentido, la hipótesis formulada entraña novedad pues, aunque no sería posible sin conocimientos previos, no está contenida en las premisas, es decir, el nuevo concepto no está contenido como algo ya sabido (Peirce, 1987, p.237). En este sentido, proponemos el razonamiento abductivo como el único cuyas consecuencias son nuevas ideas, pues construye una regla —aquello que hemos diseñado- para cada caso particular. Por otro lado, siendo la abducción conducente a una hipótesis y no a conclusiones contrastadas, la hipótesis puede adecuarse o no a lo que inicialmente preveía, por lo que debe ser verificada.

Inferimos de aquí que, el proyecto de diseño no sólo se define como un saber hacer a modo de techné aristotélica, sino que en él están tam- bién circunscritas sus características específicas, el imaginario del diseñador y los factores que lo envuelven, cuya influencia afecta al contenido, desarrollo y a los propios resultados del mismo (Gómez-Senent, 1997, p.95).

No hay, por tanto, proyecto que trate de lo general y que no esté condicionado por la realidad que lo envuelve. En este sentido, podemos decir que cuanto más específico es el campo proyectual que se estudia, más fácilmente o con mayor concreción podemos definir las estrategias que nos puedan ayudar a enfrentarnos a tal proyecto. Al respecto, Linazasoro (1984) señala que «de aquí que el discurso de la generalidad se deba acompañar del discurso acerca de la particularidad de cada situación de proyecto, ya que de lo contrario estaríamos escapándonos de un análisis acabado del problema» (p.26).

Los conocimientos particulares, forman lo que Llovet (1981) ha denominado «texto y contexto del diseño» (p.28). Esto es, el conjunto de «enunciados» que definen el "conjunto de rasgos que parecen caracterizar el objeto en cuestión» -los cuales califica como «pertinentes»- y el contexto que lo condiciona y articula en un «texto o conjunto sintáctico (y por ello sintético)». En cada proyecto de diseño, Llovet (1981, p.33) indica que estos «rasgos pertinentes» pueden organizarse dentro de un «cuadro operacional» al que denomina «cuadro de pertinencias» que incluye tanto los «rasgos pertinentes» que serán seleccionados como aquellos que podrían haberlo sido pero hemos desechado. Es decir, del vasto conjunto de rasgos incluidos en este cuadro operacional, algunos de ellos se «enlazan y engarzan» entre sí hasta configurar un todo organizado y funcional que es el artefacto.

El conjunto de enunciados del que habla Llovet (1981) es descrito por Dorst (2006, p.14) en términos de «discurso». Dorst, toma el término de los planteamientos expuestos por Foucault en La Arqueología del Saber (2002), donde lo presenta para describir el conjunto de enunciados y relaciones entre enunciados que constituyen los objetos «decibles», dentro de cada dominio.

Como en el lenguaje, en todas las áreas del diseño están presentes diversos discursos que se entrelazan en la creación de un resultado eficaz. Así, pues, en la práctica del diseño tipográfico observamos la integración de cuerpos del saber vinculados a la tecnología, la estética, la semiología, la ergonomía, la historia, la psicología, etc.

En base a esto, Dorst (2006, p.15) dispone en el diseñador la responsabilidad de conectar los diferentes discursos que deban tener cabida en el proyecto de diseño específico, lo que le obliga 
13

María Pérez Mena

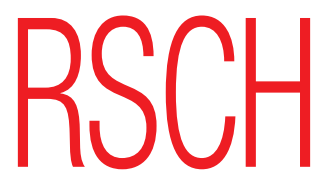

grafica: a conocer e identificar los discursos que integran los modelos que le servirán de guía en su proceso creativo. En palabras del autor ${ }^{1}$ :

Los diseñadores hacen uso de su conocimiento de los modelos de pensamiento dentro de los diferentes discursos para crear un marco en el cual la solución es posible [...]. Para que la solución sea una solución, necesita reconocerse como tal en los contextos de todos los discursos relevantes.

\section{Metodología \\ Hipótesis}

El hecho de partir de unas constricciones estructurales predeterminadas por convención y de su prioridad de uso como herramienta de la comunicación verbal, ha favorecido que el estudio del proyecto de diseño tipográfico en tanto que encrucijada de discursos o saberes haya pasado más desapercibida que otras producciones de cultura, interpretada desde enfoques más bien diversificados y planteada eminentemente en términos de oficio. No obstante, en tanto que producto cultural, el alfabeto forma parte de un contexto que lo envuelve y que es influencia directa en su devenir formal.

Si bien nuestras decisiones no son nunca neutras y responden siempre a unas condiciones antecedentes, este trabajo establece su hipótesis en la idea central de que cada una de ellas está supeditada a un orden determinado que nosotros establecemos en relación con aquello que proyectamos y que influyen directamente en el destino material del mismo, formulando, así, el proyecto de diseño tipográfico como el binomio que forman el conjunto de decisiones cuantificables (premisas tecnológicas, económicas, ergonómicas) y no cuantificables (premisas culturales: históricas, simbólicas, etc.) que construyen los discursos del proyecto.

Proponemos así, que la letra - como parte de una estructura mayor que es el alfabeto- es susceptible de ser abordada desde varias dimensiones o discursos cuya preponderancia estará vinculada a las exigencias de cada proyecto. Así, en tanto que elemento gráfico, y por tanto material, las letras responden a una dimensión tecnológica; en tanto que instrumento del habla, que debe responder a los requerimientos del lenguaje, las letras responden a una dimensión lingüística; en tanto que canal visual de la comunicación verbal, en el que se debe garantizar el intercambio de

1. Traducción libre

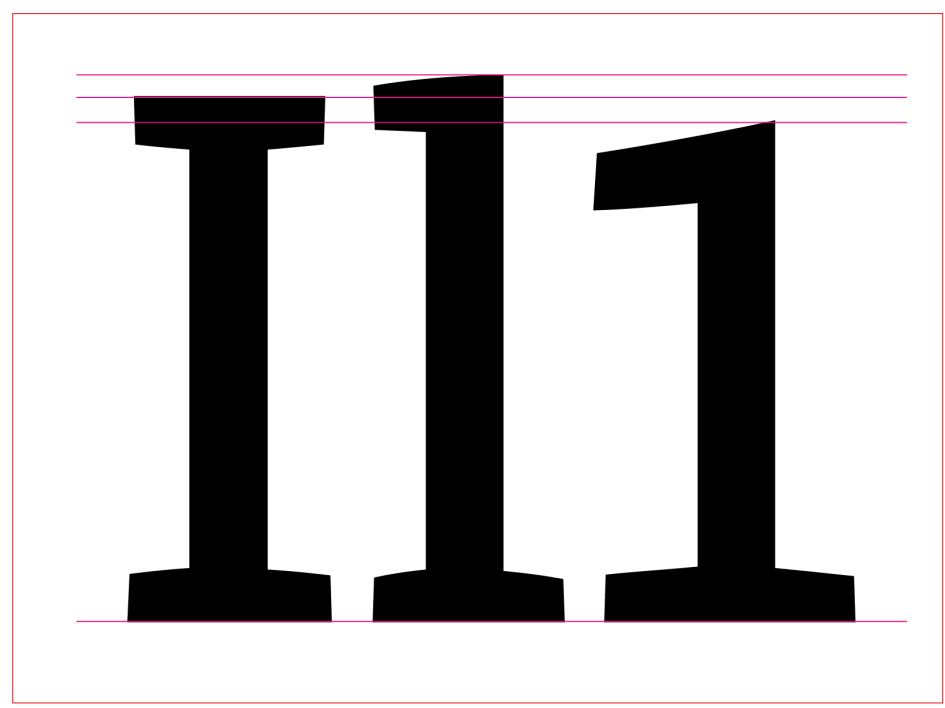

figura 6. Comparación de diferenciación en altura propuesta para mayúsculas (izquierda), ascendentes (centro) y números (derecha).

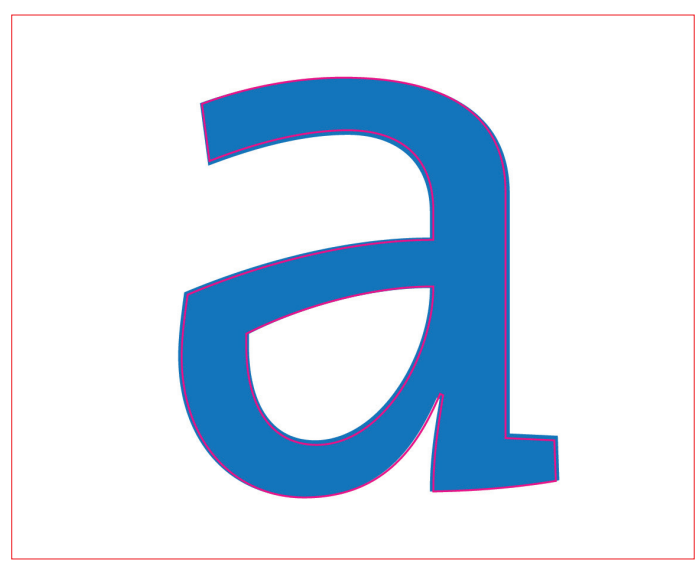

Figura 7. Comparación de espesor de la versión para uso habitual -EHUSerif- (azul) y aquella específica para cuerpos de texto en soporte impreso -EHUSerif Book- (rosa, en línea).

información, las letras responden a una dimensión ergonómica; en tanto que sustancia visual, en cuya percepción asociamos pensamientos, sentimientos o experiencias ya vividas, las letras responden a una dimensión simbólica; en tanto a que producto, inserto en una industria y una economía de mercado, las letras responden a una dimensión económica; en tanto a que forma, susceptible de generar placer estético, las letras responden a una dimensión plástica.

\section{Método}

Para abordar este trabajo, partiremos de un análisis cualitativo desde un enfoque eminentemente práctico a partir de un estudio de caso de un 
proyecto de diseño tipográfico concreto -la tipografía EHU-. Una vez descrito el proceso proyectual, se expondrán los discursos implícitos en dicho proyecto y la combinación propuesta de los enunciados que se han considerado pertinentes en cada uno de ellos.

\section{Desarrollo}

\section{Establecimiento del problema}

Ante unas necesidades concretas de identificación y diferenciación con el resto de universidades, como parte de un programa más complejo de identidad visual se propone el diseño de una tipografía corporativa para la UPV/EHU que refleje los valores de esta institución pública a través del trazo sensible de las letras.

De carácter bilingüe, esta tipografía debe resolver problemas de distinción lingüística de una manera respetuosa sin priorizar el peso visual de una sobre la otra.

En vista a su uso como herramienta de toda la comunidad universitaria, se propone el reto de responder a necesidades tanto administrativas como de señalización y, por lo tanto, implicando procesos de lectura muy diferenciados y siendo empleada en soportes diversos, incluido, evidentemente, el entorno digital.

\section{Proceso proyectual}

Para abordar el proyecto, una vez analizado el problema, se procede a la búsqueda de modelos, por un lado, de aplicación en universidades, cuyo planteamiento a priori es potencialmente similar; $y$, por otro, modelos que se ajustan a los requerimientos tecnológicos y ergonómicos que plantea específicamente el problema. Simultáneamente se produce una búsqueda en nuestro medio sociocultural de los principios simbólicos que doten de identidad a la UPV/EHU para ser interpretados en términos tipográficos en nuestro proyecto.

A través de la conjunción iterativa de momentos propositivos e iterativos propios del razonamiento abductivo en esta primera fase, cada una de las decisiones que se toma se plantea como una hipótesis cuya adecuación al problema será verificada en el uso de la futura tipografía.

Con la toma de decisiones implícita en el desarrollo de unos primeros bocetos, se procede a la digitalización de los mismos, donde se empieza a resolver el proyecto de diseño tipográfico ya no sólo en términos de sistema sino también en términos de palabra. Se hacen correcciones, se ajustan parámetros y, una vez establecidos los distintos discursos del proyecto, continuamos con la fase de producción.

\section{Resultados}

Discurso simbólico

Como principio expresivo para dotar de identidad a la tipografía corporativa de la UPV/EHU hemos recurrido a los postulados estéticos sobre la forma que genera en sus obras el artista vasco Eduardo Chillida. A partir de la elección de unas formas enraizadas en la cultura tradicional vasca, y por ello connotativas de lo vasco, Eduardo Chillida configuró un lenguaje que afirma en su sobriedad, potencia y reciedumbre, las bases de su léxico plástico, en la cultura diferenciada del medio en que vivió. Desde una actitud creadora libre, regida por el impulso, la espontaneidad y el gesto, en la obra de Chillida podemos encontrar conceptos vinculados y coincidentes con criterios generales que han determinado tradicionalmente la creación tipográfica: rigurosidad formal y un orden explícito y directamente perceptible (figura 2).

La configuración de una letra es un diálogo entre el blanco y el negro, lo que en el medio tipográfico se traduce como la relación entre la forma y la contraforma. De alguna manera, en tipografía se define el blanco como en la obra de Chillida se define el vacio, esto es, como un elemento que construye. Por eso, en tipografía, al igual que en la obra de Eduardo Chillida, podemos hablar del espacio en blanco -el vacío, el hueco- como un espacio semántico, puesto que lo no afectado por la construcción está especialmente afectado por el sentido y la intención de lo no construido.

Por otro lado, el artista busca en la naturaleza la inspiración para sus formas. Así, sus formas son ordenadas sin ser simétricas. Estas reflexiones llevaron en este proyecto a comprender la estructura de la letra desde una consideración profundamente humanista como criterio básico de configuración formal, afirmando que el proceder del ser humano está vivo, por lo que quisimos transmitir parte de esa energía vital al proyecto (figura 3).

\section{Discurso tecnológico}

Manteniendo la estructura pesada propuesta en términos de discurso simbólico, no perdemos de vista los requerimientos específicos que el medio digital establece para una adecuada lectura de textos corridos en cuerpos pequeños. Así proponemos un tipo de letra de ojo medio grande y bajo contraste que pueda ser fácilmente percibido en cuerpos pequeños a baja resolución. Su cursus transitivo y la particularidad de algunas de las letras $(a, k, x)$, permiten que la tipografía $\mathrm{EHU}$ pueda ser fácilmente identificable en este tipo de situaciones menos favorecedoras (figura 4) 


\section{Discurso ergonómico}

Proyectar una tipografía para usos tan diversos como la lectura prolongada tanto en pantalla como en papel así como para su uso en señalización, supone un ejercicio altamente complejo que requiere estudiar con detenimiento todas las situaciones. Los requerimientos gráficos de configuración de las letras en términos ergonómicos para señalización y para pantalla comparten un principio básico que observamos en la amplia altura de equis y un ojo medio generoso. En base a esto, se optó por tomar estos parámetros, así como de diferenciar la altura de las ascendentes con las mayúsculas y los números (figuras 5 y 6 ).

Dado que se detectó que en la lectura de textos (en cuerpos pequeños) en soporte impreso, este tipo de letra manchaba mucho, es decir, el "color» del texto era muy oscuro, se diseñó una versión específica para este tipo de uso, en el que manteniendo el contraste, se redujo el espesor general de la tipografía (figura 7)

\section{Discurso lingüístico}

Siendo uno de los condicionantes del proyecto la convivencia de los dos idiomas oficiales -euskera y castellano- en todas las comunicaciones de la comunidad universitaria, se optó por plantear dos versiones de la tipografía, una con remates y otra sin ellos. Con esta decisión proponíamos una convivencia respetuosa e igualitaria entre ambos idiomas al tiempo que se garantizaba su diferenciación visual en función de la lengua escogida por el receptor en su uso (figura 8)

Por otro lado, en un entorno académico existe un constante intercambio cultural a través del flujo de personal nacional e internacional con idiomas diferentes a los oficiales del territorio específico en el que se circunscribe una universidad. Aunque en una primera fase se produjo un mapa de caracteres estándar, en una segunda fase se ha propuesto ampliar este mapa para adecuarlo a las necesidades lingüísticas de los diversos idiomas que emplean escritura «latina».

Los diferentes usos previstos de manera normativa en la gramática del lenguaje, implican el uso de unas variantes tipográficas vinculadas a cuestiones estructurales - cursiva- y a cuestiones de peso - negrita- A la variante de peso de uso normativizado en términos lingüísticos, se han añadido más modelos de distinto peso con vistas a una mayor versatilidad del uso de la tipografía. Con este propósito hemos diseñado las variantes chupada, fina y extranegra (figura 9)

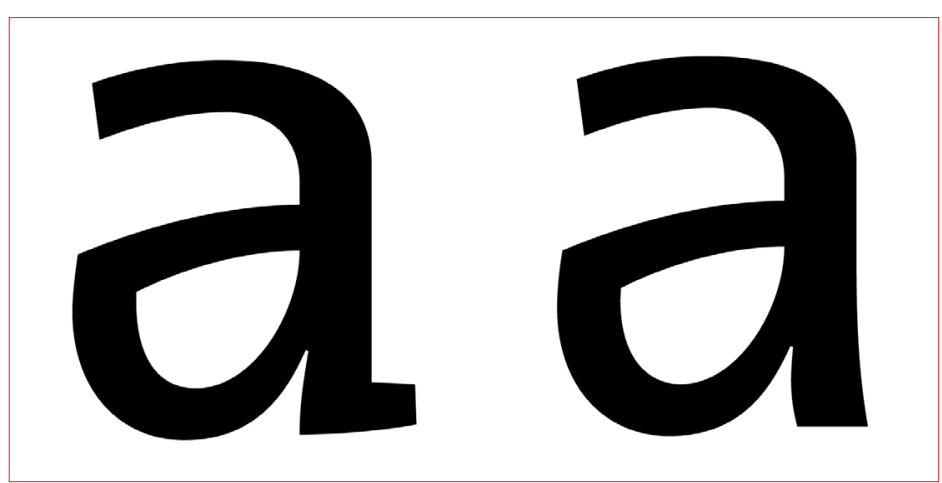

Figura 8. Comparación de la versión con remates —EHUSerif_y sin ellos -EHUSans-.

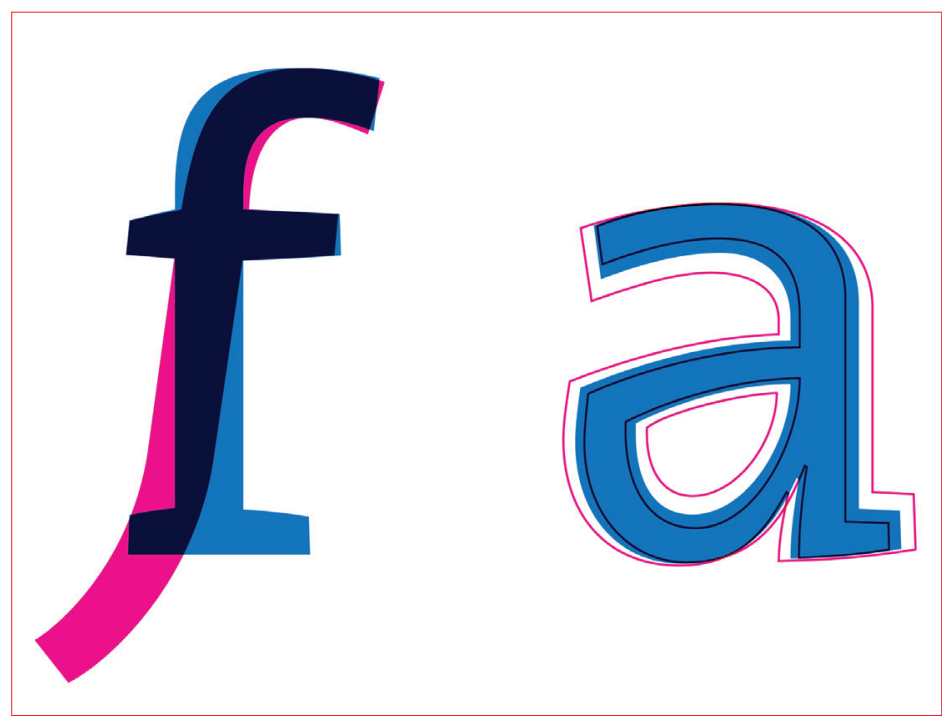

Figura 9. (Izquierda) Comparación de variante de estructura (redonda azul, cursiva rosa). (Derecha) Comparación de variante de peso (regular azul, variantes rosa).

\section{Conclusiones}

Este trabajo ha pretendido demostrar que aunque existen una serie de conocimientos generales compartidos en todo proyecto de diseño, los métodos a seguir para abordarlos no deben ser tomados nunca como una «receta» sino más bien como un «mapa» —esto es, como un modelo-, que se ajusta a las especificaciones o premisas de aquello que nos proponemos diseñar, del contexto que las envuelve y de nuestros recursos como diseñadores - que vienen dados de nuestra experiencia-. Este «mapa» es interpretado a través de un razonamiento abductivo.

Subrayamos, aquí, que hablamos de un modelo y no de el modelo. Éste no será nunca único, pues para eso tendríamos que ser capaces de tener un conocimiento exhaustivo de todas las variables que 
envuelven cada proyecto, lo cual versa ciertamente improbable. De este modo, podemos aplicar procedimientos empleados en proyectos similares o inventar otros nuevos, pero en cualquier caso, partiremos siempre de una información incompleta e imperfecta, por lo que se torna necesario establecer estrategias que respondan con la máxima eficacia posible sobre los procesos de creación. Es por esto que coge una especial importancia hablar de métodos.

Comprender los mecanismos que intervienen en la formalización de soluciones adecuadas a los fines propuestos facilita, pues, la andadura por un camino que deja un espacio muy restringido al azar, lo que lejos de limitar al diseñador lo libera, al manejar un amplio inventario en la toma de decisiones que le permite la posibilidad no solo de mejorar fines sino también medios.

Por otro lado, la progresiva complejidad de los proyectos de diseño tipográfico, dada la multiplicidad de usos posibles en un mismo proyecto y la sofisticación de una tecnología que permite un sin fin de variables formales, hace que cada vez pueda ser mayor la incertidumbre a la hora de tomar decisiones adecuadas. Es por ello que comprender el proyecto de diseño tipográfico como entrecruzamiento de saberes o discursos puede ayudar a identificar los enunciados correspondientes a cada uno de ellos en cada uno de los modelos que observamos y entender la pertinencia de los mismos en términos de uso. Esto nos puede servir para establecer márgenes de acción en las decisiones que tomamos a lo largo del proceso, reduciendo las posibilidades de incertidumbre y no dejándonos seducir por modas o por demostraciones de exaltación tecnológica.

Abordar un proyecto de diseño, en general, y de diseño tipográfico, en particular, es una actividad compleja que requiere entender los problemas en su globalidad, para poder analizarlos en profundidad a partir de los modelos adecuados y proponer soluciones eficaces, adaptadas a las necesidades de los usuarios. El carácter de oficio de la tipografía, vinculado a la tradición del trabajo centenario sobre formas establecidas por convención para una correcta lectura, ha desplazado generalmente su estudio en términos metodológicos por la comunidad académica, que se ha centrado más en cuestiones históricas, dejando las cuestiones del proceso creativo únicamente a la experiencia práctica. Es por esto que, desde este estudio, vemos la necesidad de proponer líneas de investigación en torno al proyecto de diseño tipográfico que puedan aportar conocimientos en el actual desarrollo de la tipografía como cuerpo teórico dentro del espacio del diseño gráfico pero con entidad propia. 


\section{Referencias bibliográficas}

BonsiePE, G. (1978). Teoría y práctica del diseño industrial: elementos para una manualística crítica. Barcelona: Gustavo Gili.

Costa, J. (2014). Diseño de Comunicación Visual: el nuevo paradigma. grafica, 4(2), 89-107. Recuperado de http://revistes.uab.cat/grafica/ article/view/v2-n4-costa/pdf

Cross, N. (1999). Métodos de diseño. Estrategias para el diseño de productos. México, D. F.: Limusa Wiley.

DoRST, K. (2006). Design problems and design paradoxes. Design Issues 22(3), 4-17.

FoucAult, M. (2002). La arqueología del saber. Buenos Aires: Siglo XXI Editores.

Gómez-Senent, E. (1997). El proyecto. Diseño en ingeniería. Valencia: Universidad Politécnica de Valencia.

Herrera, E., Rodriguez, D., Fernández, L. \& Pérez, M. (1997). EHU tipografia Tipografía EHU. Leioa: Servicio editorial de la Universidad del
País Vasco/Euskal Herriko Unibertsitateko Argitalpen Zerbitzua.

Hoffmann, M. (1998). ¿Hay una "lógica" de la abducción?. Analogía: Revista de Filosofía, Investigación y Difusión, XII(1). Recuperado de http://www.unav.es/gep/AN/Hoffmann.html

LinAZASORO, J., I. (1984). Apuntes para una teoría del proyecto. Valladolid: Universidad de Valladolid.

LLOVET, N. (1981). Ideología y metodología del diseño. Barcelona: Gustavo Gili.

MARINA, J.A. (1993). Teoría de la inteligencia creadora. Barcelona: Anagrama.

MARTí Font, J. M. (1999). Introducció a la metodologia del disseny. Barcelona: Edicions de la Universitat de Barcelona.

Peirce, C. S. (1987). Obra Lógico Semiótica. Madrid: Taurus Comunicación.

SteEn, M. (2013). Co-Design as a Process of Joint Inquiry and Imagination. Design Issues, 29, 16-28. Recuperado de http://www.mitpressjournals.org/doi/pdf/10.1162/DESI_a_00207 
